\title{
Implementation of a Telecardiology Service in a Health Unit in the City of Porto Alegre, Brazil: A Pilot Study
}

Francieli Giachini Esmerio,' Silvia Goldmeier, ${ }^{1}$ Eduardo Costa Duarte Barbosa, ${ }^{1 \oplus}$ Luis Marcelo Segredo, ${ }^{2}$ Rodolfo Silva, ${ }^{3}$ Maria Claudia Irigoyen, ${ }^{\circledR}$ Bruna Eibel, $^{1,4}$ Patricia Oliveira Dias ${ }^{1 \oplus}$

Instituto de Cardiologia/Fundação Universitária de Cardiologia, ${ }^{1}$ Porto Alegre, RS - Brazil

Prefeitura Municipal de Porto Alegre, ${ }^{2}$ Porto Alegre, RS - Brazil

Universidade Federal do Rio Grande do Sul - Telessaúde, ${ }^{3}$ Porto Alegre, RS - Brazil

Centro Universitário da Serra Gaúcha, ${ }^{4}$ Caxias do Sul, RS - Brazil

\section{Abstract}

Background: The implementation of Telecardiology in primary care in the city of Porto Alegre, Brazil, is a viable and promising strategy. It would decrease the distance between patient and specialized professional services by reducing unnecessary referrals and improving the quality of primary care and satisfaction of patients and health professionals.

Objective: To implement a Telecardiology service and assess user satisfaction using the CARDIOSATIS scale.

Methods: This was a pilot study developed by a partnership between the Institute of Cardiology and the Telehealth Center of Rio Grande do Sul. The study was carried out at Eri Flores-Vila Vargas health center in the city of Porto Alegre, from May to October 2019, and included 21 patients attending the health center. The descriptive analysis of data was performed using the SPSS program (Statistical Package for the Sciences) version 23. Data normality was checked using the Kolmogorov-Smirnov test. Statistical significance was set at $10 \%$.

Results: Mean age of participants was $43.8 \pm 16.1$ years. The most common risk factors in the sample were physical inactivity (81\%) and smoking (43\%). Most patients had normal electrocardiogram (ECG) readings. The time elapsed from the performance of the ECG test, transmission of the ECG traces to Telehealth, and return of the final ECG report to the health center was 0-7 days. The CARDIOSATIS scale revealed a high prevalence of "very satisfied" users for the general satisfaction domain, and only $14.3 \%$ of patients were dissatisfied with their health.

Conclusions: Telecardiology reduced the distance between patient and the specialized professional, with a high level of patient and health professional satisfaction. Our study can serve as a basis for the implementation of a telecardiology network in the city of Porto Alegre in the future.

Keywords: Telemedicine/methods; Cardiovascular Diseases; Electrocardiography; Telemedicine/trends; Telemedicine/ethics.

\section{Introduction}

In Western European countries and the United States, morbidity and mortality from coronary artery disease (CAD) is about three times higher than cerebrovascular disease. In Brazil, cardiovascular diseases (CVDs) are responsible for about one third of deaths according to DATASUS. ${ }^{1,2}$ This is particularly important considering that as longevity of populations increases, chronic diseases including CVDs become more frequent.
Porto Alegre, located in the south of Brazil, is the tenth most populous capital in the country, with an estimated $1,484,941$ inhabitants. The primary care system in the city covers areas of high social vulnerability and difficult access to specialized services. In this context, reducing geographic barriers and optimizing referrals to secondary and tertiary care would improve the provision of care and favor the local economy.

Telehealth appears as an opportunity to respond to this need using communication with information technology

Mailing Address: Bruna Eibel

Avenida Princesa Isabel, 395. Postal Code: 9062000, Porto Alegre, RS - Brazil.

E-mail: brunaeibel@gmail.com 
for information exchange. In Porto Alegre, together with the Federal University of Rio Grande do Sul (UFRGS), the Telehealth center aims to increase healthcare delivery and improve professional satisfaction.

The Porto Alegre the Pontifical Catholic University of Rio Grande do Sul (PUCRS) and the Institute of Cardiology of Rio Grande do Sul (ICFUC-RS) have implemented a telecardiology program, through Tele-ECG, and a special second opinion service to identify susceptible CVD and improve local health care. ${ }^{1,3,4}$ In this sense, telecardiology emerges as an opportunity to improve local economic, reduce the distance between the patient and specialized health services, avoiding unnecessary referrals, ${ }^{5,6}$ and improving the quality of care. ${ }^{7,8}$

Based on these observations, this study aimed at evaluating the implementation of a Telecardiology Network that includes electrocardiogram (ECG) tests in a primary care center in the city of Porto Alegre. Also, we evaluated the level of user satisfaction using the CARDIOSATIS Scale. ${ }^{9}$

\section{Methods}

This pilot study was conducted at Eri Flores Vila Vargas health center in Porto Alegre from May to October to 2019. The study was developed by a partnership between the Institute of Cardiology (responsible for interpreting the electrocardiogram tests) and the Telehealth Center of Rio Grande do Sul that guided the team.

The flowcharts of the implementation of the telecardiology service and care program at the Eri Flores Vila Vargas health center are shown in Figures 1 and 2.

The eligibility criteria were patients aged $\geq 18$ years attending the Eri Flores Vila Vargas health center, with indication for ECG, CVD risk factors (smoking, dyslipidemia, alcoholism, obesity, and sedentary lifestyle), and comorbidities such as stroke, ischemic heart disease, deep vein thrombosis and who agreed to take part in the study.

The CARDIOSATIS-USER scale was used to evaluate patient satisfaction. The instrument evaluates the domains of general satisfaction, quality of service facilities and team, access and agility, problem-solving capacity, quality of care received and satisfaction with health.

Data collection was performed using the RedCap ${ }^{\circledR}$ (Research Electronic Data Capture), a secure web application for managing online databases. ECG tests were performed using a Wincardio equipment.

Around 10 ECG exams were performed per week. The tests were then attached to the Telessaúde-RS platform, where it was evaluated and approved by a collaborating cardiologist. As this is a study developed within the Brazilian National Telehealth Program (Programa Nacional Telessaúde Brasil Redes), patients needed to be registered in the Teledermatology interface of the Telehealth Platform, adapted to the study. Also, the ECG exams needed to be sent to the teleconsultation center within 72 hours, following the deadline established by the program . It is important to remind that this study was not intended to evaluate data from the return appointment.

For analysis of ECG results, the data were entered into the platform by registered health professionals, using a login and password, which was determined by the management of the Telehealth center, allowing greater security in accessing the platform.

Ethical principles were respected, according to the ethical guidelines for research involving human subjects (Resolution 466/12 of the Brazilian National Health Council). The project was approved by the Research Ethics Committee of the ICFUC and subjected to the Eri Flores- Vila Vargas health center and the Rio Grande do Sul Telehealth center coordinators' approval.

\section{Statistical analysis}

Continuous variables with normal distribution were described as average and standard deviation, and those without normal distribution as median and interquartile range. Normality of the data was checked using the Kolmogorov Smirnov test. Categorical variables were described as absolute and relative frequencies. The level of significance adopted was $10 \%$ and the data were analyzed using the SPSS (Statistical Package for the Social Sciences) program version 23.

\section{Results}

A total of 21 patients (71.4\% women), with suggestive cardiac signs and symptoms were evaluated. Mean age was $43.8 \pm 16.1$ years, and mean body mass index (BMI) was $27.5 \pm 5.9 \mathrm{Kg} / \mathrm{m}^{2}$. Only two patients $(10 \%)$ had higher education.

Blood pressure was measured at rest according to the 7th Brazilian Guidelines on Arterial Hypertension. ${ }^{10}$ 


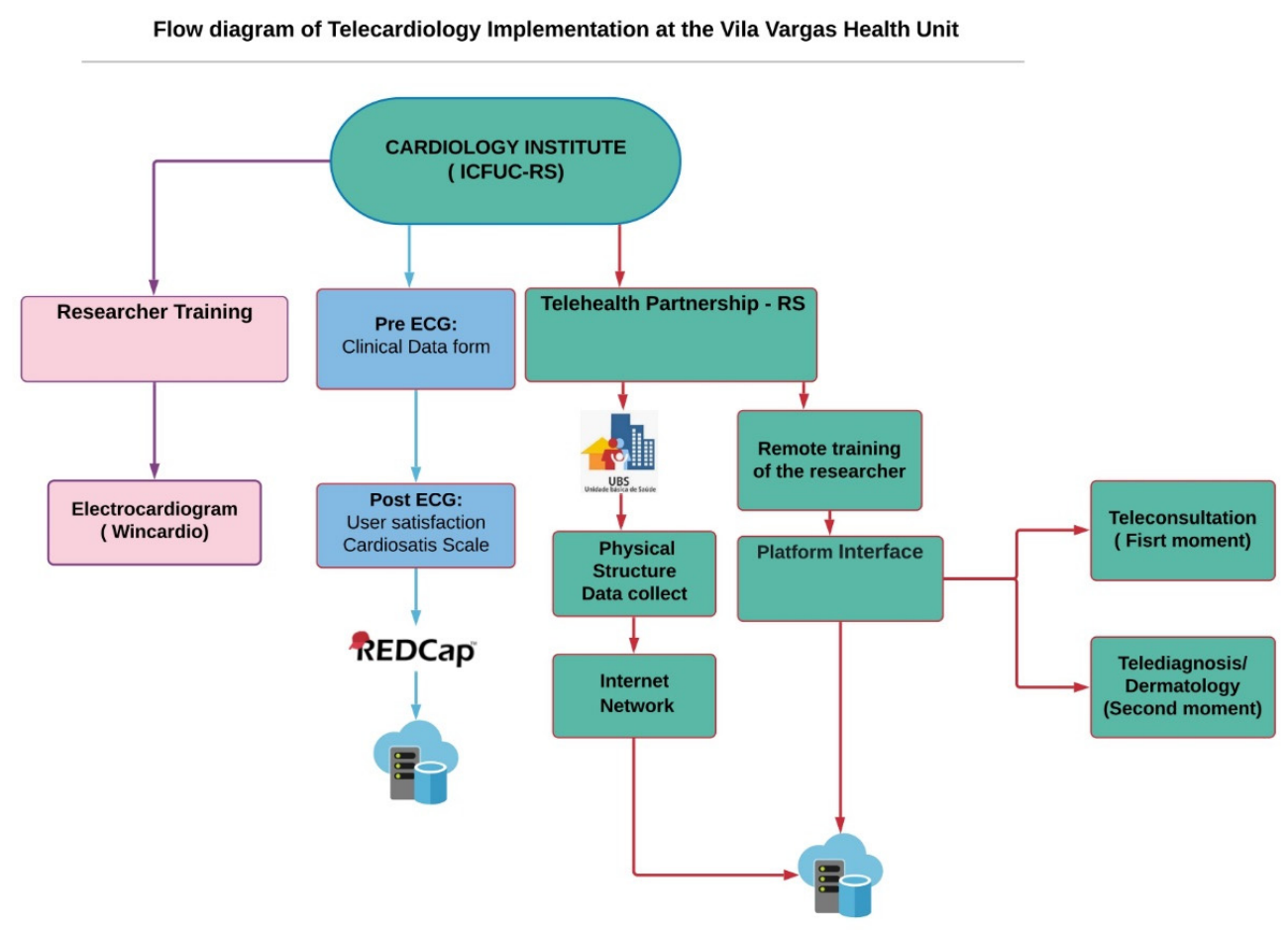

Figure 1 - Flow diagram of the Implementation of the Telecardiology at the Eri Flores Vila Vargas health center, Porto Alegre, Brazil

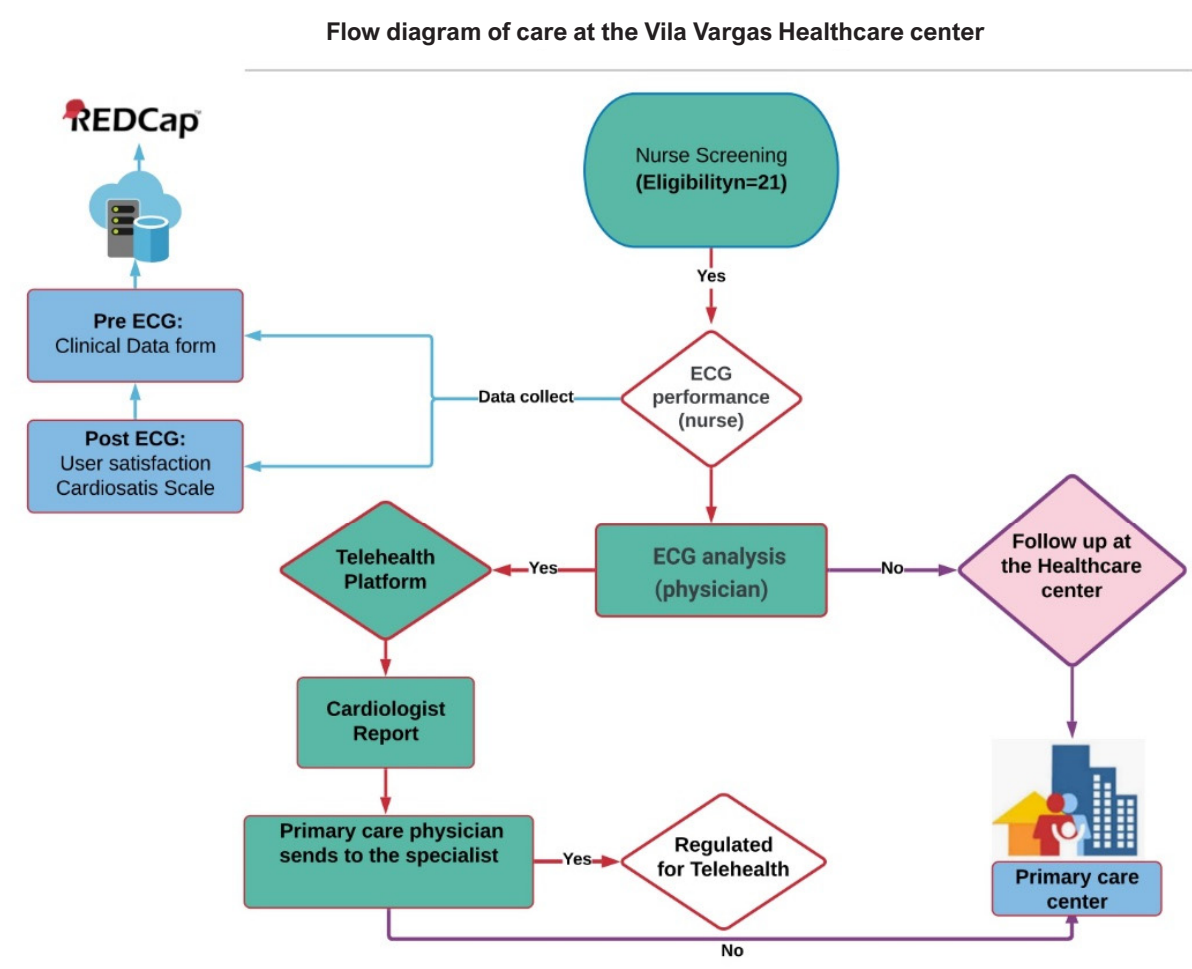

Figure 2 - Flow diagram of the Implementation of the care program at the Eri Flores Vila Vargas health center, Porto Alegre, Brazil 
Mean systolic and diastolic blood pressure was $123.3 \pm 7.9 \mathrm{mmHg}$ and $75.5 \pm 4.97 \mathrm{mmHg}$, respectively. The risk factors found were sedentary lifestyle (81\%), smoking (43\%), dyslipidemia (14.3\%), and obesity (5\%). The prevalence of diabetes mellitus was $86 \%$ in the study group (Table 1).

Analysis of the ECG reports revealed that only four patients had left ventricular hypertrophy and one had left bundle-branch block. Most patients had a normal tracing.

The median time between ECG performance and transmission of the ECG traces to Telehealth for analysis by a specialist was 0 (0-7) day. In a certain period of the data collection, it was necessary to migrate to another teleconsultation interface, the telediagnosis platform. It required adjustment and remote training of the teleconsultant cardiologist, which caused delays in sending the ECG images. The longest time for the teleconsultant to send the ECG report back to the health center was 26 days. It is worth pointing out that consultation of a cardiologist for a second opinion was not required .. Other results are described in Table 3.

The Cardiosatis Scale was used to assess patient satisfaction with the use of Telemedicine to perform the ECG test. Table 4 shows the percentage distribution of user satisfaction by the Cardiosatis dimensions. In the "general satisfaction" domain, most patients were very satisfied, and $14.3 \%$ were dissatisfied with their health.

\section{Discussion}

The results in Table 1 show a prevalence of females and an average age of 40 years in our sample. Along with an increasing longevity, mortality rates are decreasing in Brazil, although without the

Table 1 - Sociodemographic and clinical characteristics of the participants $(n=21)$

\begin{tabular}{|c|c|}
\hline Variables & Mean \pm standard deviation or Number (frequency $\%$ ) \\
\hline Age $\left(\right.$ years) ${ }^{\S}$ & $43.8 \pm 16.1$ \\
\hline Female* & $15(71.4 \%)$ \\
\hline Body mass index $x^{\S}$ & $27.5 \pm 5.9$ \\
\hline \multicolumn{2}{|l|}{ Education } \\
\hline Elementary* & $14(66.7 \%)$ \\
\hline High school ${ }^{*}$ & $5(24 \%)$ \\
\hline Superior ${ }^{*}$ & $2(10 \%)$ \\
\hline \multicolumn{2}{|l|}{ Blood pressure (mmHg) } \\
\hline Systolic ${ }^{\S}$ & $123.3 \pm 7.9$ \\
\hline Diastolic ${ }^{\S}$ & $75.5 \pm 4.97$ \\
\hline \multicolumn{2}{|l|}{ Comorbidities } \\
\hline Diabetes mellitus* & $3(86 \%)$ \\
\hline Stroke* & - \\
\hline Ischemic heart disease ${ }^{*}$ & - \\
\hline Deep vein thrombosis ${ }^{*}$ & - \\
\hline \multicolumn{2}{|l|}{ Risk Factors } \\
\hline Alcoholism* & - \\
\hline Sedentary lifestyle & $17(81 \%)$ \\
\hline Smoking* & $9(43 \%)$ \\
\hline Obesity $^{*}$ & $1(5 \%)$ \\
\hline Dyslipidemia* & $3(14.3 \%)$ \\
\hline
\end{tabular}


Table 2 - Electrocardiographic results of the study sample $(n=21)$

\begin{tabular}{lc}
\hline Electrocardiographic parameters & Total \\
\hline Normal ECG trace * & $11(52.3 \%)$ \\
Left ventricular hypertrophy* & $04(19.04 \%)$ \\
Sinus bradycardia* & $03(14.2 \%)$ \\
Left ventricular overload* & $01(04.7 \%)$ \\
Left atrial overload* & $01(04.7 \%)$ \\
Left branch block $^{*}$ & $01(04.7 \%)$ \\
\hline${ }^{*}$ Variables described as absolute $(n=21)$ and relative $(\%)$ frequency; ECG: electrocardiogram. & \\
\hline
\end{tabular}

Table 3 - Time interval between electrocardiography performance and receiving of the electrocardiogram report from the telehealth center

Time
Time from ECG performance to transmission of the electrocardiographic traces to Telehealth
Time from transmission of the electrocardiographic traces to Telehealth to transmission of the
electrocardiography report to the healthcare center
Time between sending and receiving the electrocardiography results
${ }^{*} I Q R:$ Interquartile Range

Table 4 - Percentage distribution of the user satisfaction by the CARDIOSATIS scale domains

\begin{tabular}{|c|c|c|c|c|c|}
\hline Domains & Very satisfied & Satisfied & Indifferent & Dissatisfied & $\begin{array}{c}\text { Very } \\
\text { dissatisfied }\end{array}$ \\
\hline Satisfaction with the service provided* & $19(90.5 \%)$ & $2(9.5 \%)$ & - & - & - \\
\hline Quality of facilities and the team* & $16(76.2 \%)$ & $4(19.0 \%)$ & $1(4.9 \%)$ & - & - \\
\hline Access and agility* & $16(76.2 \%)$ & $5(23.8 \%)$ & - & - & - \\
\hline Capacity of resolution* & $18(85.7 \%)$ & $3(14.3 \%)$ & - & - & - \\
\hline Quality of received care* & $18(85.7 \%)$ & $3(14.3 \%)$ & - & - & - \\
\hline Satisfaction with health* & $12(57.1 \%)$ & $6(28.6 \%)$ & - & $3(14.3 \%)$ & - \\
\hline
\end{tabular}

desired quality of life. This statement comes from the analysis of the 2018 disability-adjusted life year (DALY) and allows us to infer that health policies have been successful ${ }^{11,12}$ in controlling diseases that were previously lethal, but still incurable. ${ }^{13}$

As a result, the average lifetime of the Brazilian population increased by almost 12 years in the period. Of the approximately 26 million people who were 60 years old or more, $13.8 \%$ were 80 years old or more. However, it is known that with the advance of longevity, more people live with chronic, disabling diseases, which can compromise their autonomy and cause an economic burden on cities and states ${ }^{13}$.

In the study sample, blood pressure values were within normal limits, in accordance with the 7th Brazilian Guidelines on Arterial Hypertension. ${ }^{10}$ Among the 
comorbidities, a high prevalence of diabetes mellitus was found, corroborating previous studies that reported that at least $68 \%$ of diabetics aged 65 years or older die from heart diseases, mainly coronary artery disease. ${ }^{11,14}$

The prevalent risk factors described in this study corroborate with the literature, and reinforce the increased risk for CVD and importance of primary and secondary prevention. ${ }^{11}$ In addition, the concern with mortality from CVDs has been growing in Portuguese-speaking countries. In 1990, CVDs were the main cause of mortality in Brazil and Portugal, and currently, these conditions are related to socioeconomic conditions. Also, among the relevant risk factors associated with CVD mortality are systemic arterial hypertension and eating habits. ${ }^{12}$

The implementation of health policies, including the encouragement of healthy lifestyle habits, access to primary and secondary prevention for CVD, and treatment of cardiovascular events, is essential for the control of CVD in all countries, including Brazil. ${ }^{6}$ In this sense, the government of Brazil has been investing in Telehealth as a strategy to provide support to primary care health professionals in remote cities..$^{15}$ Take as an example the network of teleassistance service implemented in Minas Gerais State, Brazil; telecardiology with ECG and cardiology shifts were chosen as the initial focus, and later, a teleconsulting system in specialties was incorporated. ${ }^{16}$ Using an efficiency indicator, studies report that for every 100 telehealth activities taken by this teleassistance service, 80 unnecessary referrals were avoided and savings of $\mathrm{R} \$ 4.27$ were obtained for each $\mathrm{R} \$ 1.00$ invested. ${ }^{16,21}$

Analyzing the results found in this study, we realize the importance of implementing telecardiology in primary health care centers, which usually face difficulties in providing fast, qualified care and appropriate handling of patients with indication for ECG, ${ }^{7,14}$ as shown in Table 2.

Most patients in our study had normal ECG findings. This is in line with a study conducted in Rio Grande do Sul State, which described normal ECG findings in 69\% of the patients studied. ${ }^{18}$ However, the frequency of left branch block was lower compared to other studies. ${ }^{18,19}$

With a view to optimize the quality of primary care, and to avoid unnecessary referrals, time-related variables were evaluated (Table 3).

The longest time for the teleconsultant to send the test result was 26 days; which is a worrying result.
There is a consensus in the literature that the earlier the patient is seen and referred to appropriate treatment, the greater the chance of an effective intervention, and consequently reduced mortality from cardiac events. ${ }^{22,23}$ However, the staff involved in the Telecardiology program did not work exclusively in it; the activities had to be adapted to their own routines, which may have caused a delay in sending the ECG result to the Telehealth team. However, it is of note that the ECG report was sent back to the patient within 2 days, which suggests a commitment to health.

Telecardiology is practiced worldwide aiming at improving access to specialized care for users of the Brazilian Unified Health System (SUS) living in remote locations. Studies have assessed patient satisfaction with telemedicine in many health specialties and,$^{24}$ although most of them have reported that both patients and health staff express satisfaction with the care received or provided, these groups show different perceptions related to professional demand and the time spent on telemedicine practice. ${ }^{9,25}$

\section{Limitations}

In this study, inadequate facilities, and the need to change the interface of the teleconsultation platform during data collection may have reduced the likelihood of an effective intervention for the patient. Also, the time for the teleconsultant who interpreted the ECG to send back the report to the patient was longer than initially expected.

\section{Conclusions}

Telecardiology reduced the distance between the patient and the professional in the specialized service, avoiding unnecessary referrals, and improving the quality of care in primary care and patient and health professional satisfaction. The screening performed by a qualified nursing team aiming at optimizing the conduct and improving clinical outcomes, reflect the positive impact of the nurse's role on the health of SUS users. Some studies describe the cost-benefit of telemedicine for the local economy; however, this pilot project conducted at the Eri Flores Vila Vargas health center in the city of Porto Alegre may bring many economy benefits. This suggests the need for an economic analytical study at the municipal level. 


\section{Author contributions}

Conception and design of the research: Eibel B, Goldmeier S, Irigoyen MC, Esmerio F. Acquisition of data: Eibel B, Dias P, Silva R, Molina C, Segredo LM, Esmerio F. Analysis and interpretation of the data: Eibel B, Dias P, Esmerio F. Statistical analysis: Eibel B, Esmerio F. Writing of the manuscript: Eibel B, Dias P, Goldmeier S. Critical revision of the manuscript for intellectual content: Eibel B, Dias P, Goldmeier S.

\section{Potential Conflict of Interest}

No potential conflict of interest relevant to this article was reported.

\section{References}

1. Stoffels F, Sparenberg A, Fetter G, André Manica LC, Bender J, Timm R, et al. Implementing a Telecardiology Strategy in a Geriatric Institution in Pelotas - Brazil. In: Med-e-Tel 2016 Electronic Proceedings of The International eHealth, Telemedicine and Health ICT Forum for Educational, Networking and Business. 2016. Pelotas(RS); 2016. p.58-63.

2. Brasil. Ministério da Saúde. DATASUS. Brasilia;2007. [Citadoem 26julho 2020] Disponível em: http://tabnet.datasus.gov.br/cgi/tabcgi.exe?sih/cnv/niRS.def.

3. Rehnberg L, Rickard L, Chang A, Ashby L, Majkowski L, Wilson A, et al. A Successful Telecardiology Experience in Rural Communities of Rio Grande Do Sul. In: Med-e-Tel 2016 Electronic Proceedings of The International eHealth, Telemedicine and Health ICT Forum for Educational, Networking and Business. 2016, p 46-47.

4. Dias P, Siqueira E, Timm R, Silva G, Sparenberg A. Telecardiology Project of Rio Grande do Sul State, Brazil: Mistakes and Lessons from the First Years. In: eHealth: A Step towards the Universal Health Coverage in Developing Countries; 2017. p152-157.

5. Satou GM, Rheuban K, Alverson D, Lewin M, Mahnke C, Marcin J, et al. Telemedicine in Pediatric Cardiology. Circulation.2017;135(11):e648-e678. doi:10.1161/CIR.0000000000000478.

6. Lai L, Liddy C, Keely E, Afkham A, Kurzawa J, Abdeen N, et al. The impact of electronic consultation on a Canadian tertiary care pediatric specialty referral system: A prospective single-center observational study. PLoS One 2018; 13: 1-13.

7. Farah S, Andréa BR, Silva RC da, Monteiro A. Telecardiology on the Diagnostic Support of Chest Pain in Twenty-Two Emergency Care Units (UPA 24h) in The State of Rio de Janeiro. Int J Cardiovasc Sci .2018; 32:158-62.

8. Molinari G, Molinari M, Di Biase M, Brunetti ND. Telecardiology and its settings of application: An update. J Telemed Telecare. 2018;24(8):373-81.

9. Cardoso CS, Bandeira M, Ribeiro ALP, Oliveira GL, Caiaffa WT. Escalas de satisfação com o atendimento às doenças cardiovasculares: CARDIOSATIS Usuário e equipe. Cienc e Saude Colet. 2011;16(supl 1):1401-7.

10. Malachias MVB, Souza WKSB, Plavnik FL, Rodrigues CIS, Brandão AA, Neves MFT, et al. Sociedade Brasileira de Cardiologia. $7^{\text {a }}$ Diretriz Brasileira de Hipertensão Arterial. Arq Bras Cardiol 2016;107(3 Suppl 3):1-103.

11. Précoma DB, de Oliveira GMM, Simão AF, Dutra OP, Coelho OR, Izar MC de $\mathrm{O}$ et al. Updated cardiovascular prevention guideline of the Brazilian society of cardiology - 2019. Arq Bras Cardiol. 2019;113(4):787-891.

12. Nascimento BR, Brant LCC, de Oliveira GMM, Malachias MVB, Reis GMA, Teixeira RA et al. Cardiovascular disease epidemiology in Portuguese-speaking countries: Data from the global burden of disease, 1990 to 2016. Arq Bras Cardiol. 2018;110(6):500-11.

\section{Sources of Funding}

There were no external funding sources for this study.

\section{Study Association}

This study is not associated with any thesis or dissertation work.

\section{Ethics approval and consent to participate}

This study was approved by the Ethics Committee of the IC/FUC under the protocol number 2.903.890. All the procedures in this study were in accordance with the 1975 Helsinki Declaration, updated in 2013. Informed consent was obtained from all participants included in the study.

13. Feitosa-Filho GS, Peixoto JM, Pinheiro JES, Neto AA, de Albuquerque ALT Cattani ÁC, et al. Updated geriatric cardiology guidelines of the Brazilian society of cardiology - 2019. Arq Bras Cardiol. 2019;112(5):649-705.

14. Mozaffarian D, Benjamin EJ, Go AS, Arnett DK, Blaha MJ, Cushman M, et al. Executive summary: Heart disease and stroke statistics-2016 update: A Report from the American Heart Association. Circulation. 2016;133(4):447-54.

15. Brasilk. Ministério da Saúde. Portaria No 2.546, de 27 de outubro de 2011 [Citado em 06 janeiro 2020]. Disponível em: http://bvsms.saude.gov.br/ bvs/saudelegis/gm/2011/prt2546_27_10_2011.html2011

16. Marcolino A, Assis T, Riberiro A, Cardoso C, Antunes A, Resende E, et al. A telessaúde como ferramenta de apoio à Atenção Primária em Saúde: a experiência da Rede de Teleassistência de Minas Gerais. Rev Médica Minas Gerais. 2017; 27:13-9.

17. Piwońska A, Piwoński J, Szcześniewska D, Drygas W. Population prevalence of electrocardiographic abnormalities: Results of the Polish WAW-KARD study. Kardiol Pol. 2019;77(9):859-67.

18. Soares T, Irigoyen MC, Goldmeier S. The cardiac profile and electrocardiographic standard of at-height workers. Rev Assoc Med Bras. 2018;(5):448-53.

19. Schwamm LH, Chumbler N, Brown E, Fonarow GC, Berube D, Nystrom $\mathrm{K}$ et al. Recommendations for the Implementation of Telehealth in Cardiovascular and Stroke Care: A Policy Statement from the American Heart Association. Circulation. 2017;135(7):e24-e44.

20. Ribeiro ALP,Alkmim MB, Cardoso CS, Carvalho GGR, Caiaffa WT, Andrade $\mathrm{MV}$, et al. Implementation of a telecardiology system in the state of Minas Gerais: The Minas Telecardio Project. Arq Bras Cardiol; 2010;95(1):70-8.

21. Andrade MV, Maia AC, Cardoso CS, Alkmim MB, Ribeiro ALP. Costbenefit of the Telecardiology service in the state of Minas Gerais: Minas Telecardio project. Arq Bras Cardiol. 2011;97(4):307-16.

22 Maldonado JMS de V, Marques AB, Cruz A. Telemedicine: challenges to dissemination in Brazil. Cad Saude Publica. 2016;32:1-11.

23 de Souza CFQ, de Oliveira DG, Santana AD da S, Mulatinho LM, Cardoso MD, Ferreira e Pereira EB, et al. Evaluation of nurse's performance in telemedicine. Rev Bras Enferm.2019;72(4):933-9.

24 Hussain N, Edraki M, Tahhan R, Sanalkumar N, Kenz S, Akasha NK, et al. Telemedicine for diabetic retinopathy screening using an ultra-widefield fundus camera. Clin Ophthalmol. 2017;11:1477-82.

25 Whitten P, Love B. Patient and provider satisfaction with the use of telemedicine: overview and rationale for cautious enthusiasm. J Postgrad Med 2005;51(4):294-300. 